\title{
RACISMO E ANTI-RACISMO: PRECONCEITO, DISCRIMINAÇÃO E OS JOVENS ESTUDANTES NAS ESCOLAS CARIOCAS
}

YvONNE MAGGIE*

\begin{abstract}
RESUMO: O artigo tem como objetivo principal discutir os impactos das atuais políticas públicas, especialmente a chamada reserva de vagas para negros no ensino superior e o chamado estatuto da igualdade racial. Os dois projetos estão tramitando no Congresso. O artigo descreve os primeiros resultados da pesquisa realizada nos últimos dois anos em escolas do Rio de Janeiro. A autora se pergunta se temos o direito de modificar as formas tradicionais de enfrentamento da discriminação e do preconceito utilizadas por estes alunos. As escolas pesquisadas, freqüentadas por estudantes de comunidades pobres, em sua maioria, foram observadas por meio da metodologia clássica da antropologia, com estudos de caso intensivo feitos por estudantes universitários de graduação e pós-graduação. A equipe de pesquisa, coordenada pela autora, vivenciou o cotidiano das escolas e observou seus rituais, cerimônias, as aulas, os conselhos de classe e, ainda, os programas especiais ali realizados.
\end{abstract}

Palavras-chave: Escola. Racismo. Anti-racismo. Cotas raciais. Discriminação. Preconceito.

RACISM AND ANTI-RACISM: PREJUDICE, DISCRIMINATION AND YOUNG STUDENTS IN THE SCHOOLS OF THE CITY OF RiO DE JANEIRO

ABSTRACT: The main purpose of this paper is to discuss the impact of the new public policies that are being proposed as general state policies in Brazil. Two laws are currently being discussed by the $\mathrm{Na}-$ tional Congress: the quota system for entrance into public universities and the so-called Estatuto da Equaldade Racial. The author describes the first findings of a research project developed in the schools of Rio de Janeiro over the last two years. She wonders if we are entitled to change the traditional ways students used to face prejudice and dis-

* Professora titular do Departamento de Antropologia Cultural, do Instituto de Filosofia e Ciências Sociais da Universidade Federal do Rio de Janeiro (UfRJ). E-mail: yvonnemaggie@terra.com.br

Educ. Soc., Campinas, vol. 27, n. 96 - Especial, p. 739-751, out. 2006

Disponível em <http://www.cedes.unicamp.br> 
Racismo e anti-racismo: preconceito, discriminação e os jovens estudantes nas escolas...

crimination in their schools. The students of the schools participating in this research are mainly poor. According to the traditional methods of social anthropology, they were followed by graduate and undergraduate students who participated in the schools daily life and observed their rituals, ceremonies, classes and special programs.

Key words: School. Racism. Anti-racism. Racial quotes. Discrimination. Prejudice.

$\mathcal{N}$ o dia 26 de janeiro de 2005, o juiz federal substituto em exercício na $1^{a}$ Vara, Vicente De Paula Ataide Junior, exarou uma sentença na qual indeferiu um pedido de liminar impetrado por uma vestibulanda de medicina da Universidade Federal do Paraná. A estudante considerou seu direito esbulhado por não ter obtido a vaga na universidade devido ao sistema de cotas.

O sistema de cotas implantado naquela universidade ${ }^{1}$ previa a reserva de 70 vagas para o curso de medicina entre as 176 existentes assim distribuídas: 106 vagas para o vestibular geral, 35 para "afrodescendentes" e 35 para egressos de escolas públicas. A estudante que impetrou o pedido de liminar havia passado em $118^{\circ}$ lugar. $\mathrm{Na}$ sentença o juiz diz:

(...) é chegada a hora de todos nós, brancos e aquinhoados pela vida em abundância, repartirmos o valor da dívida com o povo negro, que pela sua escravidão, contribuiu significativamente para a construção das bases do nosso País. Nosso débito é alto. Você está pagando por ele agora. Meus filhos certamente o pagarão. E é possível que meus netos também o paguem. Mas não é possível negar essa dívida ou retribuir-lhes com a ingratidão ou o egoísmo. Conforme-se. Não há injustiça nisso, pelo contrário, é a justiça que ora é proclamada. Tente novamente. Você certamente conseguirá. E quando estiver nos bancos universitários e olhar para o lado, vendo seus colegas negros lá sentados com você, preenchendo um vazio de dor que antes existia, compreenda que você mesma ajudou a construir essa nova realidade, para que o Brasil começasse a se tornar uma sociedade mais livre, justa e solidária. Por essas razões, indefiro a liminar postulada.

Não será a escolha entre uma estudante que foi aprovada em $118^{\circ}$ lugar e outra que conseguiu uma vaga por ser afrodescendente uma escolha de Sofia?

Se o peso desta "reparação" vai recair sobre os jovens brasileiros, é preciso saber como se dá a discriminação e o racismo que os afeta mais 
de perto e como enfrentam esses obstáculos no seu cotidiano escolar, pois é na escola que, em princípio, estariam mais sujeitos a estes obstáculos.

Mas, antes de passar à descrição das escolas onde estudam estes jovens brasileiros, é preciso uma palavra sobre a micro-história que levou o juiz do Paraná a proferir esta sentença em 2005.

Tudo parece ter começado muito antes, ${ }^{2}$ mas só nos apercebemos da mudança no alvorecer do século XXI, quando da preparação do Brasil para a III Conferência Mundial das Naçōes Unidas de Combate ao Racismo, Discriminação Racial, Xenofobia e Intolerância Correlata, sediada na África do Sul, em 2001. ${ }^{3}$ Foi nesta Conferência que a postura do governo brasileiro perante a questão racial mudou radicalmente.

A Constituição de 1988 reconhece e condena o racismo, punindo-o como crime inafiançável. Nesse sentido, mantém a longa tradição formal republicana brasileira do a-racismo e do anti-racismo. Para a Conferência de Durban, a delegação oficial brasileira propôs "ações afirmativas" em favor da "população afrodescendente", entre elas o reconhecimento oficial da legitimidade de reparações para com a escravidão e cotas para negros nas universidades públicas.

Enquanto isso, o ministro da Reforma Agrária anunciou que iria fazer com que vinte por cento das vagas no seu ministério fossem destinadas a negros. A idéia logo se espalhou pela Esplanada dos Ministérios (o Ministério de Educação sendo exceção) e, em dezembro, o presidente da República estendeu o princípio para o funcionalismo público em geral. No mesmo mês, a Assembléia dos Deputados do estado do Rio de Janeiro aprovou por aclamação, e, portanto, sem debate, uma lei que "institui cota de até quarenta por cento para as populações negra e parda no acesso à Universidade do Estado do Rio de Janeiro e à Universidade Estadual do Norte Fluminense" (Lei n. 3.708, de 9 de novembro de 2001). Essa lei foi sendo transformada ao longo do tempo e hoje a UERJ tem $20 \%$ de vagas reservadas para negros e egressos de escolas públicas com um corte de renda de até $\mathrm{R} \$ 350,00 .^{4}$

Depois disso, e ao longo desses últimos cinco anos, 26 universidades públicas introduziram diferentes formas de inclusão em seus vestibulares, a maioria esmagadora delas com reserva de vagas para estudantes negros.

O governo federal fez ainda modificações no FIES, sistema de financiamento para estudantes em instituiçôes privadas de ensino supe- 
rior, e estabeleceu o Programa Universidade para Todos (PROUNI). Esses dois programas reservam vagas para negros e outras minorias.

Paralelamente, dois projetos de lei tramitam no Congresso Nacional, o projeto que institui cotas raciais nas universidades públicas (PL73/1999), apoiado pelo governo federal e pelo Ministério da Educação, e o Estatuto da Igualdade Racial (PL 3.198/2000), proposta do Senador Paulo Paim. Ambos os projetos estabelecem cotas para negros em todas as universidades federais e, no caso do Estatuto da Igualdade Racial, cotas para negros em todas as esferas da vida social.

O Brasil viu-se, assim, no início do novo século, com uma proposta de modificação da nação. Nossa legislação a-racial e todo o arcabouço jurídico brasileiro até a constituição de 1988 pregavam o combate ao racismo como crime inafiançável e tratava os cidadãos como iguais. Agora estes projetos de lei propõem tratar "desigualmente os desiguais", construindo assim um país legalmente dividido em duas figuras de direito - brancos e negros.

O rastilho de pólvora pegou fogo e a sociedade brasileira, compadecida com o drama dos pobres e do racismo, tudo assistiu quase que silenciosa a estas novas propostas que pululavam. Nossa sociedade passou a ser descrita por meio de uma lógica ou modelo estatístico. Essa lógica implica descrever a vida social como se fosse uma tabela estatística. Assim, aparece um discurso que fala em "fosso" entre brancos e negros. Esse novo discurso de verdade sobre o Brasil estava se tornando hegemônico quando um grupo de intelectuais, artistas e lideranças do movimento negro decidiu escrever uma Carta Pública ao Congresso Nacional e nela reafirmou os princípios universalistas da nossa sociedade e cultura. A Carta Pública gerou uma reação imediata dos proponentes das cotas, que fizeram o seu Manifesto a favor das cotas e levaram-no também aos presidentes do Senado e da Câmara. Estes dois documentos assim confrontados espelham duas posições que estão agora no debate público, exigindo do governo e dos representantes que se posicionem e reflitam sobre as conseqüências da adoção de um ou outro dos caminhos propostos. Foi nesse clima de discussão acalorada sobre que nação desejamos que redigi este ensaio, tentando refletir sobre a sentença exarada pelo juiz federal no Paraná e descrever como alguns jovens pobres cariocas sentem, pensam e reagem sobre o tema do racismo na vida cotidiana. 


\section{Preconceito e discriminação}

Ao longo dos últimos dois anos, fizemos observação participante nessas escolas, descrevendo-as em seus rituais, cerimônias e coletando entrevistas e histórias de vida. Pesquisadores, estudantes de graduação, mestrado e doutorado, principalmente meninas, mas também alguns meninos, de cores variadas, todos muito jovens e muitos deles recém-saídos das escolas pesquisadas, orientados pela coordenadora, fizeram assim estudos de caso intensivo nas escolas pesquisadas. Os jovens pesquisadores fizeram minuciosas etnografias, indo várias vezes por semana nas suas escolas, conversando com professores, estudantes e funcionários, participando de todos os rituais, como os conselhos de classe, as festas e comemorações, além de freqüentarem aulas rotineiras. Além dessa observação na escola, visitaram alunos e professores em seus locais de moradia e, em alguns casos, as entrevistas foram feitas na casa do aluno ou do professor. Mas o trabalho mais intenso foi realizado na escola. Os pesquisadores foram treinados para olhar as escolas como se estivessem em uma distante ilha do pacífico ocidental, mesmo sabendo que a ilha estava imersa em uma sociedade urbana e complexa.

Nas reuniōes semanais da pesquisa, os pesquisadores relatavam seus achados e perplexidades e não houve nenhum que não tivesse dito que estas escolas eram muito mais ricas do que se diz em geral sobre o nosso sistema educacional. Lá estavam as escolas bem com salas de aula, muitas com laboratórios de informática, bibliotecas pequenas mas razoáveis e diretores empenhados em suas tarefas. $\mathrm{O}$ que mais impressionou a todos foi, no entanto, a chamada pedagogia da repetência, que transforma todo o esforço empreendido pelas famílias e pelos alunos e mesmo pelos mestres em um eterno repetir a série cursada. Poucos se formam no ensino médio e em muitas dessas escolas a reprovação no primeiro ano do ensino médio chega a $40 \%$ dos alunos.

Em novembro de 2005, como um desdobramento da pesquisa realizada desde 2004, fizemos um survey nas 21 escolas cariocas que eram objeto de estudos de caso intensivo, sendo 19 delas da rede estadual, uma da rede federal e uma da rede particular. Entre as 21 escolas da rede estadual, 19 tinham tido baixo desempenho na avaliação feita anualmente pela Secretaria de Educação, o Programa Nova Escola, e estavam sendo objeto de uma política especialmente desenhada para melhorar o seu desempenho. As duas outras eram escolas consideradas boas nesta avalia- 
ção. A escola da rede particular e da rede federal são escolas consideradas de excelência. As 19 escolas da rede estadual estão localizadas em bairros pobres do estado ou em bairros próximos a comunidades pobres. As duas escolas de excelência localizam-se em bairros ricos da cidade. Fizemos perguntas a 391 estudantes destas escolas em uma amostra feita com base no universo de estudantes que freqüentam estas 21 escolas. É assim uma amostra das opiniōes dos estudantes dessas 21 escolas. Os resultados têm uma margem de erro de 5\% para mais ou para menos. ${ }^{5}$ Essa pesquisa mais quantitativa, sabemos, tem muitos limites e deve ser tomada apenas como uma precária bússola nesse mar agitado da realidade social, pois ela não pode ser tomada como representativa de todas as escolas cariocas e muito menos brasileiras.

O resultado da pesquisa qualitativa mostrava uma realidade em que o racismo e a discriminação, embora presentes no cotidiano dessas escolas, não eram temas de conversas e não pareciam interessar estes jovens. Vários assuntos animavam as conversas, mas o que mais era discutido era a qualidade da escola, a qualidade dos professores e a repetência. Alunos e professores discutiam a qualidade da escola e se colocavam do mesmo lado diante desta realidade. Por que os alunos eram tão reprovados? Alunos e professores colocavam a causa nos próprios alunos e na realidade brasileira, pobreza, tráfico de drogas, famílias desestruturadas. Os professores culpavam a aprovação automática que, segundo eles, teria produzido essa "débâcle" na educação do estado. Os professores, diferentemente dos alunos, diziam que eles não "queriam nada", que "não tinham jeito" e outras frases menos delicadas.

Decidimos, então, ir direto ao assunto e perguntar sobre preconceito e discriminação na escola.

Fizemos a pergunta sobre "cor/raça" do censo demográfico aos entrevistados e tivemos a seguinte distribuição: $35,5 \%$ se autodeclararam brancos, $39,5 \%$ se autodeclararam pardos e $25 \%$ se autodeclararam pretos. Verificamos que estes dados revelam uma população estudantil mais escura que a população do estado do Rio de Janeiro que, segundo o censo 2000 , compõe-se de $53,9 \%$ brancos, $33,7 \%$ pardos, $10,9 \%$ pretos e menos de $1 \%$ amarelos e indígenas. Os resultados do Exame de Ensino Médio (ENEM) em 2001 mostram que os concluintes do ensino médio naquele ano de 2001 eram compostos por $58,5 \%$ de brancos, $36 \%$ de mulatos e negros, ${ }^{6}$ sendo $30,5 \%$ de pardos, $6,3 \%$ de negros. 
A pesquisa revelou que há diferenças de percepção da discriminação e do preconceito por parte dos respondentes, tomando-os separadamente segundo a "cor/raça", mas também que há percepções semelhantes entre os respondentes.

Apenas $16,4 \%$ dos autodeclarados brancos, $20,9 \%$ dos autodeclarados pretos e $15,4 \%$ dos autodeclarados pardos disseram ter sofrido algum tipo de preconceito/discriminação na escola, o que é um indicador de que não se sentem muito discriminados.

Quando perguntamos aos que afirmaram ter sofrido discriminação quais os motivos da discriminação que sofreram, alegaram os seguintes motivos em ordem decrescente: por causa da "cor/raça"; por ser pobre; por ser mulher; por ser ou parecer homossexual; por ser gordo; por ser bom aluno e, finalmente, por ser mau aluno. Entre os $20 \%$ que disseram terem sido discriminados, $86,7 \%$ dos autodeclarados pretos; $8,3 \%$ dos autodeclarados brancos e $14 \%$ dos autodeclarados pardos afirmaram ter sofrido preconceito ou discriminação por causa de sua "cor/raça". A maioria afirmou que tinham sido outros alunos a discriminá-los. $41 \%$ dos autodeclarados brancos disseram terem sido discriminados por ser bom aluno, ao passo que $14 \%$ dos pardos afirmaram ter sofrido esse preconceito e nenhum autodeclarado preto disse o mesmo. ${ }^{7}$

Já quando perguntados se viram alguma situação de preconceito/ discriminação na escola, 40\% dos estudantes disseram que presenciaram esse tipo de situação. Mas, quando perguntamos sobre os motivos da discriminação que viram outros sofrerem, aparece uma hierarquia diversa daquela que havia surgido quando da pergunta sobre se sofreram algum tipo de discriminação. Dos autodeclarados brancos, 37\% parecem ter presenciado mais discriminação por causa da cor ou "raça", e todos os estudantes, independentemente de sua "cor/raça", viram mais pessoas sendo discriminadas por ser ou parecer homossexual.

Também perguntamos se achavam que seus mestres tendiam a discriminar seus alunos pela cor ou posição social e as respostas foram também muito impactantes. Entre os que disseram que os professores tendiam a discriminar os alunos pobres, $13,7 \%$ eram autodeclarados brancos, $11,8 \%$ autodeclarados pretos e $11,1 \%$ autodeclarados pardos.

Todavia, dos que responderam que os professores tendiam a discriminar alunos negros, 9,8\% eram autodeclarados brancos, $14,5 \%$ eram autodeclarados pretos e $13,6 \%$ eram autodeclarados pardos, o que indi- 
ca que pretos e pardos se acham mais discriminados pelos seus mestres por causa da cor. Ou seja, a maioria dos entrevistados não pensa ou sente que os professores discriminam os alunos negros ou pobres.

$16,1 \%$ dos estudantes entrevistados responderam que achavam que os professores não acreditam na vontade de estudar de alunos negros. Dentre esses, $11,3 \%$ dos autodeclarados brancos, $22 \%$ dos autodeclarados pretos e $16,5 \%$ dos autodeclarados pardos disseram que sim. Essa resposta nos leva a pensar que os autodeclarados pretos sentem mais que seus professores não acreditam na vontade de estudar de alunos negros do que os autodeclarados pardos e brancos.

Mas essa resposta, se comparada à outra dada para a pergunta sobre se os professores não acreditam na vontade de estudar de alunos pobres, talvez indique que pobreza e cor estejam associadas, pois $12,6 \%$ dos autodeclarados brancos, $20,9 \%$ dos autodeclarados pretos e $16,5 \%$ dos autodeclarados pardos acham que os professores não acreditam na vontade de estudar dos alunos pobres. Ou seja, pretos e pardos são os que mais sentem que os professores não acreditam na vontade de aprender dos alunos pobres.

Finalmente, perguntamos se na escolha de seus namorados a cor ou o nível social do parceiro era levado em consideração. Os números mostram que, na hora da escolha, a cor do parceiro é indiferente para a maioria dos entrevistados. Entre os autodeclarados brancos, 6,6\% disseram que preferiam parceiros mais escuros enquanto $4,9 \%$ disseram que preferiam mais claros, $20,5 \%$ da mesma cor e $68 \%$ disseram que era indiferente. Entre os autodeclarados pretos, 2,3\% disseram que preferiam parceiros mais escuros, 9,3\% preferiam parceiros mais claros, $5,8 \%$ preferiam parceiros da mesma cor e $82,6 \%$ achavam indiferente a cor na sua escolha de namorados. Entre os autodeclarados pardos, 5,9\% disseram que preferiam parceiros mais escuros, $8,9 \%$ preferiam mais claros, $15,6 \%$ preferiam parceiros da mesma cor e $69,6 \%$ disseram ser indiferente. Ou seja, parece que, para os entrevistados, a cor do parceiro é indiferente na hora da escolha de seus namorados, o que sugere que os estudantes são, até agora, bastante color blind nas suas escolhas amorosas. ${ }^{8}$

$\mathrm{Na}$ escolha dos namorados eles são menos indiferentes quando se trata do nível social dos seus parceiros. Entre os autodeclarados brancos, $6,6 \%$, afirmaram que preferiam mais ricos, $0,8 \%$ mais pobres e $55,4 \%$ disseram que eram indiferentes. Dos autodeclarados pretos, $9,3 \%$, disse- 
ram que preferiam parceiros mais ricos, $1,2 \%$ preferiam mais pobres, $37,2 \%$ mesma faixa de renda e para $52,3 \%$ era indiferente. Já dos autodeclarados pardos, $5,2 \%$ preferiam mais ricos, $0,7 \%$ preferiam parceiros mais pobres, $34,1 \%$ da mesma faixa de renda e para $60 \%$ o nível social do parceiro era indiferente. Os nossos entrevistados, então, parecem ser muito democráticos nas suas escolhas amorosas e não levam em consideração o nível social e a cor do parceiro na hora da escolha. No entanto, comparando o critério social e o racial, os estudantes parecem ser mais indiferentes quando se trata da "cor/raça" dos parceiros e menos indiferentes quando se trata da posição social do parceiro. ${ }^{9}$

Os números, é claro, não nos autorizam a dizer que em todas as escolas brasileiras ou mesmo cariocas os estudantes pensam desta forma. No entanto, eles confirmam o que vimos no trabalho de campo e os relatos de muitos estudantes sobre suas experiências na escola.

Preconceito e discriminação não são, até agora, tema central na vida dos estudantes dessas escolas. Mas podemos ver, pelos números, algumas tendências. Parece que os estudantes autodeclarados pretos sentem mais a discriminação e o preconceito que os autodeclarados brancos e os pardos.

No entanto, parece que essas situações de discriminação ou preconceito vividas se dão muito mais entre colegas. $\mathrm{Na}$ observação de campo, o que apareceu foram xingamentos, gozações, brincadeiras entre colegas que foram vividas como preconceito ou discriminação.

Podemos perceber uma tendência geral a uma espécie de hierarquia de xingamentos na escola. ${ }^{10}$ Assim, a referência pejorativa à homossexualidade parece ser o mais freqüente, sendo seguido por xingamentos referentes à "raça" (aí precisamos ver também se há, entre os que dizem ter visto situação de preconceito ou discriminação quanto à cor, xingamentos e referências desairosas à cor branca, o que os números não dizem), em terceiro lugar viria a pobreza, em quarto parece haver uma tendência a xingamentos quanto à gordura do colega e, por fim, ainda a ser bom ou mau aluno. ${ }^{11}$

Finalmente, os dados apresentados mostram que autodeclarados brancos e autodeclarados pretos se sentem mais discriminados por cor que os autodeclarados pardos.

Mas os números dizem algo mais. Os autodeclarados pretos parecem levar menos em consideração a cor dos parceiros que os autodecla- 
Racismo e anti-racismo: preconceito, discriminação e os jovens estudantes nas escolas...

rados brancos e pardos na escolha de seus parceiros. Dos autodeclarados pretos, $82 \%$ disseram que era indiferente a cor dos parceiros na hora da escolha, enquanto para os autodeclarados brancos e pardos apenas $69 \%$ disseram isso.

Os dados apresentados aqui talvez nos autorizem a dizer que os estudantes escolhem como estratégia desprezar marcadores "raciais" nas suas escolhas amorosas, indicando assim que suas preferências são mais baseadas nas características pessoais dos parceiros do que nas suas características grupais, por assim dizer.

Diante desses resultados, será lícito criar políticas que se afastem da estratégia até então adotada pelos estudantes cariocas? Será justo fazer recair sobre os ombros desses jovens não só a responsabilidade como as possíveis conseqüências dessa engenharia social baseada na "raça" e que entroniza marcadores "raciais" como critério de distribuição de direitos e estratégia de vida? Temos o direito de, em nome do anti-racismo, correr o risco de transformar os pátios dessas escolas em espaços divididos entre brancos e negros definidos por lei? Reparar erros do passado com uma lei que institui legalmente dois grupos raciais é a conseqüência lógica da política ora proposta para o nosso país.

Será que os resultados que acabamos de analisar, e que foram extraídos de questionários aplicados a estudantes de ensino médio do Rio de Janeiro, não seriam um alerta contra essas políticas propostas nos dois projetos de lei? Como vimos, esses estudantes escolheram um outro caminho e estratégia para enfrentar os desafios colocados pela discriminação e pelo racismo que vivem nas escolas. Criar políticas que farão recair sobre os ombros desses jovens não só a responsabilidade como as possíveis conseqüências de uma política baseada na "raça" para reparar "o erro histórico da escravidão" parece ser um caminho sem volta. Se nossos jovens hoje não se vêem divididos em grupos e se pensam como indivíduos, em várias esferas da vida social, será justo instituir, de cima para baixo, uma política ou uma "engenharia social" que os dividirá legalmente em duas metades, uma branca e outra negra, obrigando-os, logicamente, a se pensarem pertencentes a dois grupos raciais ou "étnicos" distintos?

Estas perguntas não saíram da minha cabeça ao longo desses quase dois anos de convivência nessas escolas pesquisadas.

Em 1954, Hannah Arendt (2004) posicionou-se contra o processo em curso de dessegregar as escolas nos Estados Unidos da América. 
Naquela altura, as leis que segregavam brancos e negros no sul dos EUA não haviam ainda sido abolidas e a Suprema Corte decidiu iniciar a dessegregação das escolas. Alunos negros eram obrigados a freqüentar escolas antes segregadas e onde estudavam os brancos. A filósofa alemã exilada nos EUA posicionou-se contra esta decisão, apesar de ser uma decisão considerada libertária para a maioria dos americanos. Segundo ela, era impossível lutar contra o racismo sem abolir as leis que separavam os cidadãos em duas "raças". O anti-racismo, segundo a autora, teria que começar retirando do estado toda e qualquer regra baseada em "raça", pois estas leis violam o princípio mais fundamental da República.

A solução ora apresentada como política pública, a reserva de vagas para negros nas universidades federais e o chamado Estatuto da Igualdade Racial parecem atacar pelo lado mais frágil. Eles propõem a construção legal de barreiras intransponíveis entre os futuros candidatos ao ensino superior e que estudam em escolas públicas e, fazendo isso, reproduzem o que Arendt via nos EUA naqueles anos de 1950:

A série de acontecimentos que se seguiu à decisão da Suprema Corte, depois dos quais o governo se comprometeu a travar a sua batalha pelos direitos civis na esfera da educação e escolas públicas, impressiona pelo senso de futilidade e amargura necessária, como se todas as partes envolvidas soubessem muito bem que nada estava sendo realizado sob o pretexto de que alguma coisa estava sendo feita. (Arendt, 2004, p. 265)

Recebido e aprovado em agosto de 2006.

Notas

1. O sistema implantado naquela IFES previa a autodeclaração da cor do candidato. No entanto, foi criada uma comissão para averiguar fraudes. Sobre a implantação do vestibular naquela IFEs, ver Bevilaqua (2005).

2. Ver, sobre a história da construção desse discurso de verdade, Monteiro (2003).

3. Sobre um histórico desse debate, ver Fry e Maggie (2005).

4. Sobre o caso da UERJ, ver Machado (2004) e Ramos (2005).

5. Ver, sobre a pesquisa, o relatório de 2006 disponível em: <www.observa.ifcs.ufrj.br>

6. O Exame Nacional de Ensino Médio utilizou as categorias "negro" e "mulato" em vez de "preto" e "pardo", como é tradicional em pesquisas censitárias desde o final do século XIX.

7. Foi difícil estabelecer essa hierarquia porque apenas $20 \%$ dos entrevistados afirmaram que tinham sofrido preconceito, o que dificulta qualquer análise mais acurada. 
Racismo e anti-racismo: preconceito, discriminação e os jovens estudantes nas escolas...

8. Não foi possível cruzar as preferências por sexo, porque os números são insuficientes.

9. Para uma análise mais fina sobre as escolhas amorosas e a cor dos parceiros, ver Moutinho (2005).

10. Ver, sobre a relação dos brasileiros com a homossexualidade, DaMatta (1997).

11. Este resultado parece ser consistente com as recentes pesquisas sobre o tema, conforme pode ser visto em Carrara e Ramos (2005).

\section{Referências Bibliográficas}

ARENDT, H. Reflexões sobre Little Rock. In: AREndT, H. Responsabilidade e julgamento. São Paulo: Companhia das Letras, 2004.

BEVILAQUA, C.B. A implantação do "Plano de metas de inclusão racial de social" na Universidade Federal do Paraná". Relatório de 2005 apresentado no seminário da Rede Observa: Acompanhando as ações afirmativas no ensino superior. Disponível em: <www.observa.ifcs.urfj.br >. Acesso em: 16 jul. 2006.

CARRARA, S.; RAMOS, S. Política, direitos, violência e homossexualidade: Pesquisa 9a Parada do Orgulho GLBT - Rio 2004. Rio de Janeiro: CEPESC, 2005.

CARVALHO, J.J. Inclusão étnica e racial no Brasil. A questão das cotas no ensino superior. São Paulo: Attar, 2005.

DAMATTA, R. Tem pente aí? Reflexōes sobre a identidade masculina. In: CAldAs, D. (Org.). Homens: comportamento, sexualidade, mudança. São Paulo: SENAC, 1997.

FRY, P.H. A persistência da raça: ensaios antropológicos sobre o Brasil e a África Austral. Rio de Janeiro: Civilização Brasileira, 2005.

FRY, P.H.; MAGGIE, Y. O debate que não houve. In: FrY, P. A persistência da raça: ensaios antropológicos sobre o Brasil e a África Austral. Rio de Janeiro: Civilização Brasileira, 2005.

GÓES, J.R.P. O racismo vira lei. O Globo, Rio de Janeiro, 16 ago. 2004.

GÓES, J.R.P. Tema em debate: cotas raciais. O Globo, Rio de Janeiro, 14 jul. 2006. 
MACHADO, E.A. Desigualdades raciais e ensino superior: um estudo sobre a introdução das leis de reservas de vagas para egressos de escolas públicas e cotas para negros, pardos e carentes da UERJ: 2004. Tese (doutorado) - Programa de Pós-Graduação em Sociologia e Antropologia da Universidade Federal do Rio de Janeiro. Rio de Janeiro.

MAGGIE, Y. A reserva de vagas na universidade brasileira. Estudos Avançados, São Paulo, v. 50, n. 18, p. 67-80, $2004 a$.

MAGGIE, Y. Cotas raciais - construindo um país dividido. Revista do Programa de Pós-Graduação em Economia, Rio de Janeiro, v. 6, p. 153-162, $2004 \mathrm{~b}$.

MAGGIE, Y. Uma nova pedagogia racial? Revista da USP: Dossiê Especial, n. 68, dez. 2005-jan./fev. 2006.

MAGGIE, Y. A escola vista por dentro: Relatório 2006 apresentado no seminário da Rede Observa: Acompanhando as ações afirmativas no ensino superior. Disponível em: <www.observa.ifcs.urfj.br>. Acesso em: 16 jul. 2006.

MAIO, M.C.; SANTOS, R.V. Política de cotas raciais, "os olhos da sociedade" e os usos da antropologia: o caso do vestibular da Universidade de Brasília (UnB). Horizontes Antropológicos, Porto Alegre, ano 11, n. 23, p. 181-214, jan./jun. 2005.

MOUTINHO, L. Razão, cor e desejo: uma análise comparativa sobre relacionamentos afetivo-sexuais inter-raciais no Brasil e na África do Sul. São Paulo: UNESP, 2004. v. I.

MONTEIRO, F.D. Retratos em branco e preto, retratos sem nenhuma cor: a experiência do disque-racismo da Secretaria de Segurança Pública do estado do Rio de Janeiro. 2003. Dissertação (mestrado) - Programa de Pós-Graduação em Sociologia e Antropologia da Universidade Federal do Rio de Janeiro. Rio de Janeiro.

RAMOS, C. Lei de cotas na universidade: o caso das universidades estaduais do Rio de Janeiro. 2005. Dissertação (mestrado) - Programa de Pós-Graduação em Sociologia e Antropologia da Universidade Federal do Rio de Janeiro. Rio de Janeiro. 